\title{
R12 - AVALIAÇÃO DA APLICAÇÃO DA PLATAFORMA DE MICROARRANJOS LÍQUIDOS NO DIAGNÓSTICO DA SÍFILIS
}

$\underline{\text { Marcelle Bral de Mello }}{ }^{1}$, Bernardo de Oliveira Loureiro ${ }^{1}$, Leila Botelho Rodrigues da Silva $^{1}$, Bruna de Paula Fonseca e Fonseca ${ }^{1}$, Christiane de Fátima Silva Marques ${ }^{1}$, Edimilson Domingos da Silva ${ }^{1}$, Antônio Gomes Pinto Ferreira ${ }^{1}$.

${ }^{1}$ Laboratório de Tecnologia Diagnóstica, Bio-Manguinhos, Fiocruz

Objetivo: Avaliar o desenvolvimento de uma nova plataforma para o diagnóstico de Sífilis, utilizando uma metodologia multiteste, com potencial aplicação em um sistema automatizado de diagnóstico.

Métodos: A metodologia diagnóstica selecionada para este estudo é baseada na tecnologia de microarranjos líquidos com microesferas magnéticas. Estas microesferas são coradas internamente através de uma mistura de dois fluoróforos em diferentes concentrações, o que resulta em microesferas diferencialmente codificadas. Essa característica permite a análise simultânea de dezenas de analitos diferentes (reação multiplex). As microesferas servem de suporte para diversos tipos de moléculas (principalmente proteínas e ácidos nucleicos). Para o presente trabalho, um antígeno específico do agente etiológico da Sífilis (Treponema pallidum) foi acoplado na superfície das microesferas, mediante uma ligação covalente entre amina (antígenos) e carboxila (microesferas). Na primeira etapa do teste, os anticorpos presentes nas amostras positivas ligam-se ao antígeno acoplado às microesferas, criando um complexo antígenoanticorpo. Após um período de incubação e sucessivas lavagens, é adicionado o sistema revelador, composto por um anticorpo anti-IgG humano conjugado com Ficoeritrina. A leitura dos resultados, expressos em valores da mediana da intensidade de fluorescência (MFI), foi realizada pelo equipamento Labscan 100 (Luminex). Para a análise, foram selecionadas 103 amostras positivas para Sífilis, e 10 amostras negativas. Todas as amostras foram previamente avaliadas com dois testes diagnósticos estabelecidos (VDRL e DPP).

Resultados: Com a exceção de duas amostras, os resultados obtidos com a nova metodologia corroboraram os resultados prévios dos testes considerados como base comparativa. Baseado nos dados obtidos, o novo ensaio apresentou uma sensibilidade de $98 \%$ e especificidade de $100 \%$. 
Conclusão: $\mathrm{O}$ ensaio baseado na plataforma de microarranjos líquidos mostrou-se uma boa ferramenta para o diagnóstico da Sífilis, principalmente para laboratórios que possuam alta capacidade de processamento de amostras. $\mathrm{O}$ teste apresenta potencial de redução de custos, volume de amostra necessário e tempo de dedicação do operador à realização do teste, uma vez que o ensaio pode ser totalmente automatizado. A melhoria na sensibilidade do teste pode ser atingida com a incorporação de outros antígenos do $T$. pallidum visando a detecção de outros epítopos que possam não ter sido identificados pelo antígeno utilizado neste estudo. 